\begin{abstract}
Classical labour supply theory is one of the most sophisticated parts of labour economics. Yet, there is no compelling theoretical reason to believe in an outcome on a classical labour supply curve and it is unclear whether it is a good empirical description of the way in which labour markets actually work. This paper uses the techniques of search theory to analyse the impact of changes in the tax system on incentives to work when individuals do not have flexibility of hours within jobs. It is shown how the traditional comparative statics are of some use but are rarely the whole story and some comparative statics results are surprising. For example, it is shown how a revenue-neutral increase in marginal tax rates will increase incentives to work.
\end{abstract}

This paper was produced as part of the Centre's Labour Markets Programme 


\section{Labour Supply, Search and Taxes}

Alan Manning 
Series Editor: Graham Ingham

Published by

Centre for Economic Performance

London School of Economics and Political Science

Houghton Street

London WC2A 2AE

(C) Alan Manning, submitted October 1999

ISBN 0753013649

Individual copy price: $£ 5$ 


\section{Labour Supply, Search and Taxes}

\section{Alan Manning}

1. Introduction 1

2. The Canonical Model of Labour Supply and 2

Competitive Equilibrium

3. A Simple Search Model 3

4. Variation in Hourly Wages $\quad 4$

4.1 Changes in average tax rates 6

4.2 Changes in marginal tax rates 9

5. The Impact of Tax System on Hours of Work 11

$\begin{array}{ll}\text { 6. Conclusions } & 13\end{array}$

$\begin{array}{lr}\text { Figures } & 15\end{array}$

$\begin{array}{ll}\text { Appendix } & 19\end{array}$

References $\quad 22$ 


\section{Acknowledgements}

I am grateful to Richard Blundell and seminar participants at Berkeley, Brigham Young and Stanford Universities.

Alan Manning is at the Department of Economics and the Centre for Economic Performance, London School of Economics. 


\section{Labour Supply, Search and Taxes}

\section{Alan Manning}

\section{Introduction}

Most work on labour supply (see Blundell and MaCurdy, 1998, for a recent survey) starts from what Pencavel, 1986, calls the canonical model in which individuals freely choose how many hours of work they supply to the market at a constant hourly wage. Yet, in many circumstances individuals do not seem to have such flexibility over their hours of work (see Stewart and Swaffield, 1997, for UK evidence on the extent to which individuals feel constrained in the hours they can work) and the model seems inappropriate. Supporters of the labour supply methodology often then fall back on the argument that "even if each employer specified not merely the wage rate but also the number of hours each employee is expected to work, provided the wage offer does not vary systematically with the stipulated hours and provided the entire range of hours of work is covered by the employers' offers then a continuous linear budget constraint arises from the aggregation over many employers' wage-hours packages" (Pencavel, 1986, p.36). If there were strong theoretical reasons to believe that individuals should be on their classical labour supply curves then one might be tempted to give these arguments serious weight. But, there is no reason to believe that individuals would be on a classical labour supply curve in a perfectly competitive equilibrium so that there is little reason to privilege the canonical model in the way that is usually done. There is a danger that the traditional conclusions about the impact of taxes are not robust to reasonable alternative assumptions about the flexibility of hours within jobs.

This paper relaxes the assumption that individuals can freely choose their hours within jobs and goes to the opposite extreme in considering a labour market where there is no variation in hours within jobs. This assumption about the flexibility of hours within jobs is as arbitrary as the assumption made in the canonical model so that one should think of this paper as an investigation into the robustness of conventional results, an exercise that is important once one realizes there is no reason to pay special attention to the canonical model.

If individuals are simply offered a single income-hours package the only decision is whether to take the job or not: a paper on the impact of the tax system on this decision would be neither long nor interesting. This paper complicates the individual's decision by using a search model: how the optimal search for jobs responds to taxes is an interesting question even if individuals have little or no control over the hours they work within jobs. This is not just an exercise: search theory has proved its value in many parts of labour economics e.g. it has been widely used to analyse to analyse the impact of unemployment insurance on incentives to find and take jobs (e.g. Mortensen, 1977). But surprisingly little work has been done on the impact of the tax system (honourable exceptions being Pissarides, 1983, and Ljungqvist and Sargent, 1995a,b). There is a curious dichotomy in which analysis of unemployment insurance generally uses a search framework while analysis of tax changes uses a labour supply framework; although both sets of papers are about the impact of changing incentives to work.

The plan of the paper is as follows. In the next section we outline the argument for why the canonical model of labour supply is not generally a feature of a competitive equilibrium. We then introduce the search model and analyse how changes in marginal and average tax rates might be expected to affect labour supply on both the extensive and intensive margins. Some of the results of classical labour supply theory remain relevant but they are rarely the complete story and some results are surprising given the conventional wisdom. For example, it is shown that a revenueneutral increase in marginal tax rates will increase labour supply on the extensive margin. 


\section{The Canonical Model of Labour Supply and Competitive Equilibrium}

In this section we briefly outline the argument that a classical labour supply curve is not generally a feature of a competitive equilibrium, an argument that can be traced back to Lewis (1969). Consider a firm with a production function $\mathrm{A}(\mathrm{N}, \mathrm{h})$ where $\mathrm{N}$ is the level of employment and $\mathrm{h}$ is the hours of work of each worker. Suppose that all workers have a utility function $\mathrm{u}(\mathrm{y}, \mathrm{h})$ where $\mathrm{y}$ is income and $\mathrm{h}$ are hours of work. Assuming that all workers are identical keeps matters simple but nothing of importance depends on it.

In a competitive market there will be a going rate of utility, $\mathrm{u}_{0}$, which the firm has to offer to attract any workers. It is efficient for the firm to offer an income-hours package and to choose a level of employment to maximize profits subject to offering workers the market level of utility i.e. $\mathrm{N}, \mathrm{y}$ and $\mathrm{h}$ will be chosen to solve the following problem:

$$
\max A(N, h) \& y N \quad \text { s.t. } u(y, h) \$ u_{0}
$$

The first-order conditions for the solution to this problem can be written as:

$$
\begin{gathered}
A_{N}(N, h) \& y \quad \text { ' } 0 \\
A_{h}(N, h) \% \mu u_{h}(y, h) \quad, 0 \\
\& N \% \mu u_{y}(y, h) \quad \text { ' } 0
\end{gathered}
$$

where $\mu$ is the multiplier on the constraint. We are interested in the conditions under which the equilibrium outcome is on a labour supply curve as conventionally defined i.e. where one can decentralise the equilibrium by the firm simply offering a fixed hourly wage and allowing workers a free choice in their hours of work. In this case, the equilibrium outcome must satisfy the following first-order condition:

$$
y \cdot u_{y}(y, h) \% h \cdot u_{h}(y, h) \quad ' 0
$$

Using (3) and (4) this can be written as:

$$
y N \& h A_{h}(N, h) \quad ' \quad 0
$$

and, then using (2), this can be written as:

$$
N A_{N}(N, h) \& h A_{h}(N, h) \quad ' \quad 0
$$

This condition is only satisfied if the production function can be written as $\mathrm{A}(\mathrm{Nh})$. In this case the firm is happy to leave the choice of hours to the worker as the employer can always respond 
by altering the number of workers leaving total hours worked and the total wage bill unchanged.

The intuition for this result is very simple. Suppose that $A(N, h)=N a(h)$ so that there are constant returns in employment. In a competitive equilibrium the income earned by working $h$ hours will be $\mathrm{a}(\mathrm{h})$. Given a utility function $\mathrm{u}(\mathrm{y}, \mathrm{h})$, individuals will choose hours $\mathrm{h}$ which maximise $u(a(h), h)$. This can be represented graphically in Figure 1a where we have drawn a(h) as initially a convex function of hours worked because of set-up costs but eventually concave as exhaustion sets in (as in Card, 1990).

As can be seen from Figure 1a, there is no reason for the line of tangency at the optimal income-hours combination to go through the origin which would be required to decentralise the competitive equilibrium by setting a constant hourly wage as is assumed in the canonical labour supply model. One can only guarantee this if $\mathrm{a}(\mathrm{h})$ is linear in $\mathrm{h}$ as represented in Figure $1 \mathrm{~b}$. This is simply a special case of the result described above as the production function can be written as $\mathrm{A}(\mathrm{N}, \mathrm{h})=\mathrm{aNh}$ in this case.

Where the equilibrium outcome is not on a traditional labour supply curve, there are a number of ways in which the optimal contract could be implemented. The employer could use a more sophisticated labour contract and leave the worker to make the final decision on hours. In this case detailed knowledge of the employment contract would allow the researcher to work out the marginal hourly wage faced by a worker and, hence, estimate the marginal rate of substitution between consumption and leisure. But, if the employer chose to attain the optimal outcome by simply fixing the hours required of the worker, no amount of detailed knowledge of the labour contract would enable one to estimate the marginal rate of substitution. In the classical case of Figure $1 \mathrm{~b}$, there would seem to be some practical advantage in the employer setting a linear contract as the optimal contract is independent of the preferences of workers so the employer does not need that information. But, this argument is not valid if we move away from the classical case as knowledge of preferences is needed to design the optimal employment contract.

As described in the introduction, this paper is based on the assumption that there is no flexibility of hours within jobs. This can be thought of as assuming that a(h) has the form represented in Figure 1c so that the hours worked within jobs are not sensitive to the tax system. One should think of this as being the opposite extreme to the assumption embodied in Figure 1b: by looking at the extremes, one would hope to get some idea of how robust standard results are. Ideally, one would like to work with the general case represented in Figure 1a (as that is probably the most realistic case) but that is rather too complicated.

\section{A Simple Search Model}

In this section we shall present a simple search model that we will use for our analysis of the impact of the tax system on incentives to work. To keep matters simple we will assume that the individual is in a static environment with a utility function $\mathrm{u}(\mathrm{y}, \mathrm{h})$ where $\mathrm{y}$ is income and $\mathrm{h}$ is hours of work. We will make the assumption (common in search theory) that all income is consumed when earned. ${ }^{1}$

The existing papers that have tried to marry search and labour supply (e.g. Burdett and Mortensen, 1978; Blundell at al, 1998) have made the assumption that jobs differ in the hourly

${ }^{1}$ A large part of research into labour supply has been concerned with relaxing this assumption but we will not pursue this further here (see Blundell et al, 1998, for a search model that does not make this assumption though does assume perfect flexibility of hours within jobs). 
wages they offer but that hours can be freely chosen within jobs i.e. they assume that individuals find it difficult to find a good job in terms of the hourly wage but that, once they have found a job, they have no difficulty in working their desired hours in that job. For the reasons given in the introduction we want to dispense with this assumption of perfect flexibility in hours within jobs. Our approach will be to go to the opposite extreme and to assume that job offers are characterised by an income-hours package with no flexibility in hours worked. If workers want to find a job with their desired level of hours, they need to look for it. We will write the distribution function of income conditional on hours as $\mathrm{F}\left(\mathrm{y}^{*} \mathrm{~h}\right)$ and the marginal distribution function of hours as $\mathrm{J}(\mathrm{h})$. We will use lower case letters to denote density functions. We also assume that the distribution of earnings offers is unaffected by the tax system: this is consistent with the assumption usually made in the canonical labour supply model of the exogeneity of the pre-tax wage but it is important to realise that most general equilibrium models (e.g. Burdett and Mortensen, 1998; Lockwood and Manning, 1993; Pissarides, 1998) would suggest that there is likely to be some impact of the tax system on the distribution of pre-tax earnings ${ }^{2}$. It is an important task to get some idea of the general equilibrium incidence of changes in the tax system but one which needs much more work than is going to be provided in this paper.

As the purpose of this paper is to show how conventional results on the impact of the tax system on work incentives do not necessarily carry over to a search model, we are not going to analyse the general case. In particular, we consider the following two extreme assumptions about the job offer distribution:

- all variation in job offers is in the hourly wage at fixed hours

- $\quad$ all variation in job offers is in hours at a fixed hourly wage

Let us consider these two cases in turn.

\section{Variation in Hourly Wages}

In this section we adopt the simplifying assumption that all jobs offer the same hours so that the variation in jobs is only in the hourly wage offered. For notational simplicity, we will drop the ' $h$ ' argument from the distribution of job offers and simply write it as $F(y)$. Denote the value function for an unemployed worker by $\mathrm{V}^{\mathrm{u}}$, and the value function for a worker employed at earnings y by $\mathrm{V}(\mathrm{y})$. $\mathrm{V}^{\mathrm{u}}$ will be given by:

$$
\begin{gathered}
\mathrm{d}_{r} V^{u} \quad{ }^{\prime} \quad u\left(b \& t_{u}, 0\right) \% ?_{{ }_{\mathrm{r}}} \max \left[V(x) \& V^{u}, 0\right] d F(x) \\
\quad u\left(b \& t_{u}, 0\right) \% ?_{{ }_{u}}\left[V(x) \& V_{r}^{u}\right] d F(x)
\end{gathered}
$$

where $b$ is the flow of income when unemployed, $d_{r}$ is the interest rate, $?_{u}$ is the arrival rate of job offers when unemployed, $\mathrm{F}(\mathrm{y})$ is the earnings offer distribution, $\mathrm{t}(\mathrm{y})$ is the net tax paid if employed at income $y$ and $t_{u}$ is the net tax paid if unemployed. In deriving the second line, we have used the fact that the reservation wage, $r$, must satisfy $V^{u}=V(r)$. For workers in employment we have:

${ }^{2}$ Given this it might be best to think of the analysis that follows as giving the impact of a 'scheme' that affects only a small fraction of the population and hence does not have large general equilibrium effects. 


$$
\mathrm{d}_{r} V(y) \quad u(y \&(y), h) \& \mathrm{~d}_{u}\left[V(y) \& V^{u}\right] \% ?_{{ }^{2}} \mathbf{r}_{y}[V(x) \& V(y)] d F(x)
$$

where $d_{u}$ is the rate of job loss and $?_{e}$ is the arrival rate of job offers when employed.

Evaluating (9) at $\mathrm{y}=\mathrm{r}$, and subtracting this from (8) leads to:

$$
u(r \& t(r), h) \%\left(? ?_{e} \& ?_{u}\right)_{r}[V(x) \& V(r)] d F(x) \quad ' \quad u\left(b \& t_{u}, 0\right)
$$

Now differentiating (9) leads to:

$$
\frac{M(y)}{M} \cdot \frac{u_{y} \cdot\left[1 \& t_{y}(y)\right]}{\mathrm{d} \%_{e}(1 \& F(y))}
$$

where $d=d_{u}+d_{r}$. Now integrate the term under the integral sign in (10) by parts to obtain:

$$
\operatorname{ma}_{r}[V(x) \& V(r)] d F(x) \quad \text { ' } \underset{r}{\mathrm{~m} M} \cdot[1 \& F(x)] d x
$$

Substituting (11) into (12) and then putting it back into (10) yields the following expression for the reservation wage:

$$
\left.u(r \& t(r), h) \quad \%\left(?_{e} \& ?_{u}\right)\right)_{r} \frac{u_{y} \cdot\left[1 \& t_{y}(x)\right][1 \& F(x)]}{\mathrm{d} \%_{e}[1 \& F(x)]} d x \quad \text { ' } u\left(b \& t_{u}, 0\right)
$$

(13) is essentially the standard expression for the reservation wage, modified for the presence of the tax system. For example, the marginal tax rate appears in the integral term as this represents the utility return from obtaining a job with a higher pre-tax wage. One feature of (13) which will be useful later is that the level of utility at the reservation wage is above (below) the level of utility when unemployed as on-the-job search is less (more) effective than off-the-job search.

The case analysed here can only be used to study the extensive margin of labour supply (i.e. whether the individual is in work or not): there is obviously no interest in the intensive margin as all job offers are assumed to have the same hours. As "the strongest empirical effects of wages and non-labour income on labour supply are to be found on the extensive margin" (Heckman, 1993, p.118), this margin is probably the more interesting one empirically. The probability of being in work, $p$, is given by:

$$
p \quad \frac{?_{u}[1 \& F(r)]}{\mathrm{d}_{u} \%_{u}[1 \& F(r)]}
$$

(14) implies that a study of how the reservation wage responds to changes in the tax system contains (in our model) all the information required to determine how the employment rate will respond. In traditional labour supply analysis, it is conventional to decompose changes in the tax system into changes in average and marginal tax rates holding the other part of the tax system 
constant: let us apply this methodology in the search framework.

\subsection{Changes in average tax rates}

First, consider a rise in the average tax rate holding the marginal tax rate constant. Let us do this in the purest way possible by assuming that an amount of income $t$ is deducted from each individual whether they are employed or unemployed and whatever their income. If we assume that leisure is a normal good, the classical result is that a reduction in post-tax income can only induce an individual who previously was not working to start working: nobody who is already working will become inactive. As we shall see, this result does have some useful content in the search model but it is not the whole story. The following proposition gives us the general result:

Proposition 1:An increase in the average tax rate $t$ at all income levels has the following impact on the reservation wage:

$$
\begin{gathered}
\frac{\mathrm{d} \%_{u}(1 \& F(r))}{\mathrm{d} \%_{e}(1 \& F(r))} \cdot\left(\frac{\mathrm{M}}{\mathrm{M}}\right), \\
{[u_{y}(r \& t(r), h) \& u_{y}\left(b \& t_{u}, 0\right) \&\left(?_{u} \& ?_{e}\right) \cdot \underbrace{}_{r} \frac{u_{y y} \cdot\left[1 \& t_{y}(x)\right][1 \& F(x)]}{\mathrm{d} \%_{e}[1 \& F(x)]} d x]}
\end{gathered}
$$

Proof: Simple differentiation of (13).

The sign of $(\mathrm{M} / \mathrm{M})$ depends on the sign of the right-hand side of (15). The general case is rather hard to analyse as there are circumstances in which we can put an unambiguous sign on this and others in which we cannot. So, we will proceed by analysing some special cases to build up a picture of the different effects at work. First, let us start by assuming that on- and off-the-job search are equally effective so that $?_{\mathrm{u}}=?_{\mathrm{e}}$.

Proposition 2a: If $?_{\mathrm{u}}=?_{\mathrm{e}}$ then:

(i)

$$
\operatorname{sgn}\left(\frac{\mathrm{M}}{\mathrm{M}}\right) \quad, \quad \operatorname{sgn}\left(u_{y}(r \& t(r), h) \& u_{y}\left(b \& t_{u}, 0\right)\right)
$$

(ii) If:

$$
\frac{\& u_{y y} u_{h}}{u_{y}} \% u_{y h}>(<) \quad 0
$$

and $\mathrm{u}_{\mathrm{y}}>0, \mathrm{u}_{\mathrm{h}}<0$ for all $(\mathrm{y}, \mathrm{h})$ then $(\mathrm{M} / \mathrm{M})>(<) 0$.

Proof: See Appendix. 
The final expression in (17) is familiar from classical labour supply theory as the sign of this determines whether leisure is a normal good. If it is then an increase in the average tax rate lowers the reservation wage and increases work just as it does in classical labour supply theory.

There is a simple diagrammatic representation of this result. Figure 2a shows a traditional indifference curve between post-tax income and hours of work. We have drawn the indifference curve corresponding to the level of utility obtainable when unemployed. The reservation wage will be given by the level of pre-tax income which yields a level of post-tax income to put the individual on this indifference curve (represented by UU) at hours of work $h$. If the average tax rate is raised by taking away $t$ at all income levels then the individual will be on a lower indifference curve when unemployed, represented by VV. One way of expressing the statement that leisure is a normal good is to say that the marginal utility of income falls as we increase hours of work while moving along an indifference curve. In diagrammatic terms this means that indifference curves become further apart as one increases hours of work: we have drawn the indifference curves in Figure 2a in this way. This means that, after the rise in the average tax rate, the individual will be strictly better-off at the initial reservation income level than they would be if unemployed. As the reservation income level is chosen to yield utility equal to that obtainable when unemployed this means the individual will reduce the reservation income and this means they are more likely to be in work.

However, one should hesitate before concluding that the predictions of classical labour supply theory and the search model are identical in this case. For the classical result, one only needs the normality of leisure to hold at the point chosen by the individual: to be able to sign (16) unambiguously one needs it to hold for all hours below the level worked. In diagrammatic terms, normality of leisure at the point chosen means that, at a given level of income, the gap between indifference curves is increasing in hours. But, (16) requires the comparison of the marginal utility of income at two distinct points so requires a comparison of the gap between indifference curves at these points.

To see the potential difference, consider a simple case where the utility function can be written in the form $\mathrm{u}(\mathrm{y}, \mathrm{h})=\mathrm{f}(\mathrm{y})-$ ? $(\mathrm{h})$ where $\mathrm{f}(\mathrm{y})$ is a strictly concave function. Leisure is then normal at all income-hours combinations that might be chosen by a utility-maximising individual in a classical labour supply model. But, in a search model whether raising average tax rates raises the incentives to work depends on whether $r$ is greater than $b$ which depends on whether ? (h) is greater than ? (0). The conventional assumption is that utility is everywhere decreasing in hours so that ? (h) $>$ ? (0) and $[\mathrm{r}-\mathrm{t}(\mathrm{r})]>\left[\mathrm{b}-\mathrm{t}_{\mathrm{u}}\right]$ which implies a rise in average tax rates increases the incentive to work. However there is some, albeit not overwhelming, evidence that, over some range, utility might be increasing in hours. For example, some structural search models (e.g Narendranathan and Nickell, 1985; Narendranathan, 1993) try to estimate the disutility of labour and find that, controlling for income, work is preferred to unemployment. Also, evidence from self-reported satisfaction suggests that, controlling for income, the unemployed are less happy than those in employment (see, for example, Clark and Oswald, 1994, or Winkelmann and Winkelmann, 1998): the greater suicide rates among the unemployed might also be construed in a similar way. All of this is irrelevant in the classical model as, at points that might be chosen by an individual, leisure is always normal ${ }^{3}$. But, in the search model, it is not irrelevant: if the individual is at a point where the marginal utility of income is decreasing in hours but where ? $(\mathrm{h})<?(0)$ then an

${ }^{3}$ Although a non-convexity in the budget set (e.g. because of time and money costs of going to work) requires, even in the classical case, attention to more than the local normality of leisure and can produce comparative statics similar to those of the search model described here. 
increase in the average tax rate will increase the incentive to work. This example is illustrated in Figure $2 b$ where an increase in the average tax rate will reduce the incentives to work.

Next let us consider the case $?_{\mathrm{u}}>?_{\mathrm{e}}$.

Proposition 2b: If $?_{\mathrm{u}}>?_{\mathrm{e}}$ then:

(i)

$$
\frac{\mathrm{d} \%{ }_{u}(1 \& F(r))}{\mathrm{d} \%_{e}(1 \& F(r))} \cdot\left(\frac{\mathrm{M}}{\mathrm{M}}\right)<u_{y}(r \& t(r), h) \& u_{y}\left(b \& t_{u}, 0\right)
$$

(ii) If leisure is everywhere a normal good and $\mathrm{u}_{\mathrm{h}}<0, \mathrm{u}_{\mathrm{y}}>0$ everywhere then an increase in the average tax rate lowers the reservation wage and increases labour supply.

\section{Proof: See Appendix.}

The intuition for the result in part (ii) is very straightforward. From Proposition $2 \mathrm{a}$ we know that if hours always decrease utility and leisure is a normal good then the marginal utility of income is lower at the reservation wage than when unemployed even if the level of utility is the same. But with $?_{\mathrm{u}}>?_{\mathrm{e}}$ the level of utility at the reservation wage is higher than that when unemployed (see (13)) which further lowers the marginal utility of income at the reservation wage.

Finally, let us consider the case $?_{\mathrm{u}}<?_{\mathrm{e}}$.

Proposition 2c: If $?_{\mathrm{e}}>?_{\mathrm{u}}$ then:

$$
\frac{\mathrm{d} \%{ }_{u}(1 \& F(r))}{\mathrm{d} \%{ }_{e}(1 \& F(r))} \cdot\left(\frac{\mathrm{M}}{\mathrm{M}}\right)>u_{y}(r \& t(r), h) \& u_{y}(b \& t(b), 0)
$$

Proof: See Appendix.

There is no second part to this Proposition as it is not so easy to provide plausible sufficient conditions for when the reservation wage rises or falls with an increase in the average tax rate, for the following reason. We know that when $?_{\mathrm{u}}<?_{\mathrm{e}}$ we have $\mathrm{u}(\mathrm{r}-\mathrm{t}(\mathrm{r}), \mathrm{h})<\mathrm{u}\left(\mathrm{b}-\mathrm{t}_{\mathrm{u}}, 0\right)$. If we are prepared to make the assumption that leisure is everywhere a normal good and $\mathrm{u}_{\mathrm{h}}<0$ then there are two effects working in opposite directions. First there is the effect that if the reservation utility was equal to the level of utility when unemployed the sign of the right-hand side of (19) will be negative. But the fact that the reservation utility is lower raises the marginal utility of income at the reservation utility level. The net effect depends on which effect is stronger. For example, if the utility function is of the form $\mathrm{u}(\mathrm{y}, \mathrm{h})=\mathrm{f}(\mathrm{y})-$ ? $(\mathrm{h})$ then the sign of $(\mathrm{M} / \mathrm{M})$ depends entirely on whether $[\mathrm{r}-\mathrm{t}(\mathrm{r})]$ is larger or smaller than $\left[\mathrm{b}-\mathrm{t}_{\mathrm{u}}\right]$. The greater effectiveness of on-the-job search tends to make $[\mathrm{r}-\mathrm{t}(\mathrm{r})]$ smaller than $\left[\mathrm{b}-\mathrm{t}_{\mathrm{u}}\right]$, while any disutility of work tends to make it higher, the net effect depending on which effect is the stronger.

One does not need to worry about whether on- or off-the-job search is more effective if 
the agent is risk-neutral so that we can write $\mathrm{u}(\mathrm{y}, \mathrm{h})=\mathrm{y} ?_{1}(\mathrm{~h})+?_{2}(\mathrm{~h})$. In this case, changes in the average tax rate alter neither the marginal tax rate nor the marginal utility of income, so leave unchanged the part of the expression for the reservation wage which involves the job offer arrival rates.

Proposition 2d: If $\mathrm{u}_{\mathrm{yy}}=0$ then:

$$
\operatorname{sgn}\left(\frac{\mathrm{M}}{\mathrm{M}}\right) \quad, \quad \operatorname{sgn}\left[u_{y}(r \& t(r), h) \& u_{y}\left(b \& t_{u}, 0\right)\right] \quad \operatorname{sgn}\left[?_{1}(h) \& ?_{1}(0)\right]
$$

Proof: Simple substitution in (15)

If $?_{1}^{\prime}(\mathrm{h})$ has the same sign everywhere then $(\mathrm{M} / \mathrm{M})$ has the same sign so that if leisure is everywhere normal (which, for this utility function, amounts to the assumption that $?_{1}{ }^{\prime}(\mathrm{h})<0$ for all h) then an increase in the average tax rate will reduce the reservation wage and increase the probability that an individual is in work. However the caution from the discussion of Proposition 2a also applies here: if utility is increasing in hours over some range then it may be the case that an increase in average tax rates raises the incentives to work even though leisure may be normal at the level of hours chosen.

One way of summarizing the above discussion is that the traditional labour supply effect which depends on the normality of leisure is still at work when we alter the average tax rate. Although one has to worry about whether normality holds at hours other than the ones actually worked. But there is an additional effect if workers are risk-averse: the direction of which depends on the sign of $\left(?_{\mathrm{u}}-?_{\mathrm{e}}\right)$ which can be interpreted as the relative effectiveness of on-the-job and off-the-job search.

\subsection{Changes in marginal tax rates}

In traditional labour supply analysis one normally considers changes in the marginal tax rate, holding the average tax rate constant at the chosen income-hours combination so that the individual is assumed to be able to be as well-off as before if they maintain their behaviour. It is not possible to do exactly this exercise in a search model because there is no single income level to which the individual can be assigned. Raising the marginal tax rate on wages above the reservation wage inevitably increases the average tax rate for all higher wages making the individual worse off even if they behave in the same way as before.

But there is a notion of a 'pure' change in marginal tax rates holding the average tax rate constant that can be analysed in the search model. Suppose we consider a change in the tax system that raises marginal tax rates for all wages above the reservation wage but changes the average tax rate in such a way that total expected taxes from employment are left unchanged if the behaviour of the worker is unchanged.

Let us define $\mathrm{T}^{\mathrm{u}}$ to be the expected value of taxes from a currently unemployed worker and $\mathrm{T}(\mathrm{y})$ the expected value from a worker currently employed at income y. By analogy to (8) and (9), we must have:

$$
\mathrm{d}_{r} T^{u} \quad ' \quad t_{u} \% ?_{{ }_{u} \mathrm{n}_{r}}\left[T(x) \& T^{u}\right] d F(x)
$$




$$
\mathrm{d}_{r} T(y) \quad ' \quad t(y) \& \mathrm{~d}_{u}\left[T(y) \& T^{u}\right] \% ?_{e^{2}}[T(x) \& T(y)] d F(x)
$$

Differentiating (22) we have that:

$$
T_{y}(y) \quad \cdot \frac{t_{y}(y)}{\mathrm{d} \%_{e}(1 \& F(y))}
$$

Integrating (21) and (22) by parts, using (23) and evaluating (22) at $\mathrm{r}$ we then have:

$$
\begin{aligned}
& \mathrm{d}_{r} T^{u} \quad t_{u} \% ?_{u}[1 \& F(r)] .\left[T(r) \& T^{u}\right] \% ?_{{ }_{u}} \frac{t_{y}(x)(1 \& F(x))}{\mathrm{m}_{r} \%} d x \\
& \mathrm{~d}_{r} T(r) \quad, \quad t(r) \& \mathrm{~d}_{u}\left[T(r) \& T^{u}\right] \% ?_{e} \frac{t_{y}(x)(1 \& F(x))}{\mathrm{mi}_{r} \%_{e}(1 \& F(x))} d x
\end{aligned}
$$

(24) and (25) show that the impact of a change in the tax system on the expected tax take will inevitably be different for unemployed workers and workers employed at different wages. It is natural to alter the marginal tax rate holding constant the expected tax take from an unemployed worker, $\mathrm{T}^{\mathrm{u}}$, as this ensures that the total expected tax take from a worker entering the labour market is unchanged.

A rise in marginal tax rates will raise the final term in (24) which, other things equal, will raise $T^{\mathrm{u}}$ : this is because such a rise in marginal tax rates raises the average tax take on workers paid above the reservation wage. To keep $\mathrm{T}^{\mathrm{u}}$ constant there need to be some off-setting changes in other parts of the tax system. By inspection of (24) and (25) this could be a fall in $t_{u}$ or a fall in $t(r)$. A fall in $t_{u}$ will transfer resources from employed to unemployed workers: unsurprisingly one can show that such a change will always raise the reservation wage and hence reduce labour supply. However it does not seem appropriate to describe such a change as a rise in marginal tax rates holding the average tax rate constant. So we will consider the other change: a fall in $t(r)$ sufficient to keep $\mathrm{T}^{\mathrm{u}}$ constant if behaviour is unchanged. This change keeps the level of payments to the unemployed constant so is simply a redistribution of the tax burden among workers employed at different wages. The consequence of such a change is summarized in the following Proposition.

Proposition 3: If $\mathrm{u}_{\mathrm{y}}=0$, an increase in the marginal tax rate on wages above the reservation wage with overall tax revenue from employment unchanged must reduce the reservation wage and increase incentives to work.

Proof: See Appendix.

Although this result appears to be dramatically at odds with the prediction of classical labour supply theory, the intuition for the result is very simple. The change in the tax system increases the attractiveness of employment at low wages relative to unemployment but reduces the relative attractiveness of employment at high wages. But, in deciding on the reservation wage it is the 
attractiveness of employment at low wages that is important and the change means that there is an incentive to lower reservation wages. This result, in a different model and expressed in a different way can be found in Pissarides (1983) and Ljunqvist and Sargent (1995a,b).

Although at first sight this result may look very different to the classical one, some reflection reveals that it is not so different. Suppose that we have a canonical model in which all individuals have the same hourly wage but, because of individual heterogeneity, they choose different incomehours combinations. This situation is represented in Figure 3 where, for simplicity, we have assumed that there are some time and money costs of going to work (as in Cogan, 1981) so that there is a discontinuity in the budget constraint. In Figure 3 the budget constraint is the vertical line at zero hours of work and then AA. Someone with preferences UU will be on the margin of participation, while someone with preferences VV will not. Suppose that there is the (realistic) requirement that all individuals face the same tax schedule. If the marginal tax rates faced by those in work is raised but no attempt made for the change to be revenue-neutral then the budget line might twist from $\mathrm{AA}$ to $\mathrm{AB}$. One can see that the average tax rate will rise for all individuals in employment. If the change to the tax system is to be revenue-neutral at unchanged behaviour then $\mathrm{AB}$ must be shifted up, perhaps to $\mathrm{CC}$. This inevitably induces a negative correlation between the change in the average tax rate and income; with the average tax rate falling for those with the lowest incomes. The individual with preferences UU who was previously at the margin of labour market participation now strictly prefers to work and some individuals who previously chose not to work will now want to do so. Hence, such a change in the tax system can only induce extra participation.

Finally we should briefly consider what happens if workers are risk-averse. Then an increase in marginal tax rates also has the benefit, from the point of view of the worker, of improving the provision of income insurance when employed. This makes work even more attractive relative to non-work and strengthens the result of Proposition 3.

The result in Proposition 3 might appear to make an increase in marginal tax rates costless. But while this might be the case in the simple model considered here, one needs to be aware of potentially important adverse effects in richer models. First high marginal tax rates will act as a disincentive to higher effort in jobs. Also, a high marginal tax rate is likely to have an adverse impact on search intensity as it reduces the reward from higher-wage jobs.

\section{The Impact of the Tax System on Hours of Work}

The previous section examined the extreme case where the only variation in job offers was in the hourly wage and there was no variation in hours. In this section we analyse the other extreme case where the only variation in jobs is in the hours offered and all jobs offer the same hourly wage i.e. the distribution of income conditional on hours is given by:

$$
\begin{gathered}
F\left(y^{*} h\right), 0 \text { for } y<w h \\
F\left(y^{*} h\right), 1 \text { for } y \$ w h
\end{gathered}
$$

where $\mathrm{w}$ is the hourly wage. We can now discuss the impact of taxes on both the intensive and extensive margins of labour supply. One potentially appealing feature of this model is that it can nest the classical model of labour supply which assumes (26) and, in addition, that the level of hours desired by the individual has positive support in $\mathrm{j}(\mathrm{h})$ and that the labour market is frictionless (i.e. ? ${ }_{\mathrm{u}}=4$ ) so that the individual can immediately get a job at their desired hours level. All of these 
are strong assumptions e.g. there is a lot of evidence to suggest that part-time jobs have lower hourly wages associated with them.

Now jobs have two dimensions, we need to modify the workers' decision rule so that they have a reservation utility level ${ }^{4}$. With the assumption in (26) one can represent this as a maximum hours level they will be prepared to work and a minimum hours level so that only jobs offered between these two levels will be accepted by the worker. The desired level of hours given by the classical labour supply curve must lie within the acceptable range.

As it will turn out that the theoretical predictions are ambiguous we keep matters simple and assume that $?_{\mathrm{u}}=?_{\mathrm{e}}$ so that on-the-job and off-the-job search are equally effective. In this case the reservation utility level is simply the level of utility obtainable when unemployed. Let us consider the impact of a pure change in average tax rates on hours of work. Let us assume that the existing tax system is $\mathrm{t}(\mathrm{y})$ and that an amount $\mathrm{t}$ is going to be deducted whatever the level of income. Let us denote by $h_{1}$ the lowest level of hours the worker will accept and $h_{u}$ the highest level of hours. These two levels must satisfy:

$$
u\left(w h_{l} \& t\left(w h_{l}\right) \& \mathbb{t}, h_{l}\right) \quad ' \quad u\left(w h_{u} \& t\left(w h_{u}\right) \& \mathbb{t}, h_{u}\right) \quad ' \quad u\left(b \& t_{u} \& t, 0\right)
$$

If the tax system is continuous and there are no fixed costs of going to work then we will have $h_{1}=0$ but those are both strong assumptions (one can think of them corresponding to the assumption that $b=0)$. We can prove the following result:

Proposition 4:If leisure is everywhere a normal good then $h_{1}$ must be non-increasing in the average tax rate and $h_{u}$ must be non-decreasing.

\section{Proof: See Appendix.}

The intuition for this result is straightforward. The increase in the average tax rate makes the individual worse off. When leisure is a normal good this makes them more likely to take jobs further away from their desired level which means increasing the maximum hours they are prepared to work and decreasing the minimum hours.

The impact of the change in the average tax rate on the extensive margin of labour supply is straightforward. As the rise in $t$ raises the maximum acceptable hours and reduces the minimum acceptable, the fraction of jobs that are acceptable to the worker must rise and, hence, the probability of being in employment will also rise.

However, the effect on average hours worked is ambiguous. If one is interested in the impact on average hours worked (either conditional on working or unconditional) then one needs to weight the hours acceptable to the worker by the probability of the worker working those hours. If the labour market is frictionless then, with probability one, the worker will be employed at their optimal hours (assuming this is in the support of the offered hours distribution) so it does not make any sense to look at any other levels of hours. But, if the labour market is not frictionless then there will be a distribution of hours which will depend on variables like job arrival rates and job destruction rates so that one cannot a priori say anything about how measures of average hours will be affected by changes in average tax rates.

${ }^{4}$ This will obviously remain the case even if the distribution of income given hours is not of the form given in (26). 
What about changes in marginal tax rates?

Proposition 5:An increase in marginal tax rates together with a change in average tax rates to keep expected tax revenue unchanged at unchanged behaviour will reduce $h_{1}$ and increase $h_{u}$.

\section{Proof: See Appendix.}

It should be obvious from this result that the probability of being in employment rises but that the impact on measures of average hours will again be ambiguous and subject to the same discussion as of Proposition 4.

This section has looked at the impact of changes in the tax system on hours worked when the only source of dispersion in job offers is dispersion in offered hours and the hourly wage is the same in all offered jobs. Even in this case the classical results do not carry over unless the market is frictionless.

\section{Conclusions}

This paper has examined the impact of changes in the tax system on labour supply in a labour market where individuals have no flexibility of hours within jobs but must search for 'good' jobs. This way of thinking about labour supply deserves attention not only because of the proved usefulness of a search framework in other parts of labour economics but also because the canonical model of labour supply is based on arbitrary assumptions about the flexibility of hours within jobs. It is then important to have some idea of the robustness of traditional comparative statics results. Some results from the traditional labour supply literature (e.g. the role of the assumption of the normality of leisure) have been shown to be useful in a search model but they are rarely the whole story. Many of the results are quite weak and ambiguous which suggests that economic theory may not be as much use as a guide to empirical specification as is sometimes assumed. And some of the results, notably the impact of a revenue-neutral rise in marginal tax rates, go directly against the conventional wisdom.

However, this paper is a long way from a complete analysis of the issues raised or a demonstration of the superiority of the search approach over the classical approach. In particular, classical labour supply analysis is largely a practical subject devoted to the empirical analysis of the impact of tax and welfare systems. However, the approach described here should not be too difficult to implement empirically. An equation like (13) can be made estimable with assumptions about the distribution of wage offers an individual faces and a knowledge of the tax-benefit system. Empirical research could either study the durations of spells of non-employment (as the literature on the impact of welfare systems often has done) or the probability that an individual is in employment at a particular point in time (as the literature on labour supply normally has done).

There are also a number of theoretical areas where the analysis could be usefully extended. First, classical labour supply theory finds it difficult to make a meaningful distinction between inactivity and unemployment and it is hard to relate the definitions of these states used in the construction of labour market statistics to theoretical concepts. There has been some empirical work (Ham, 1982, 1986; Blundell, Ham and Meghir, 1987) on trying to introduce unemployment in a more realistic fashion but search theory offers a more natural way to do this. In labour market statistics those classed as unemployed must be without a job, have looked for work in the recent past (typically four weeks) and be available to start work within a certain period (normally two weeks) i.e. it is a definition largely based on the intensity of job search. Burdett and Mortensen 
(1978), Burdett et al (1984) and Blundell at al (1998) use this to distinguish between inactivity and unemployment by using a search model in which search effort is endogenous; and assuming that those who expend more than a certain amount of time and/or money in job search are the unemployed. We would then expect the tax system to have some impact on search intensity and the proportions of the workforce who are inactive or unemployed.

Secondly, this paper has concentrated on the impact of the tax system on the outflow rate from unemployment. From (14) this is only half of the story about the determinants of the probability of being in employment: we also need a model of the impact of the tax system on job destruction (see Mortensen and Pissarides, 1994, for a model of job destruction in a search framework). Such a model would also help the framework used here to address issues about the dynamics of employment and labour market participation, issues that have been central to much recent work on traditional labour supply.

So, there is much more research in this area that could and should be done before it can legitimately pretend to be a viable alternative to more traditional analyses of labour supply. 
Figure 1a

The Optimal Income-Hours Contract: The General Case

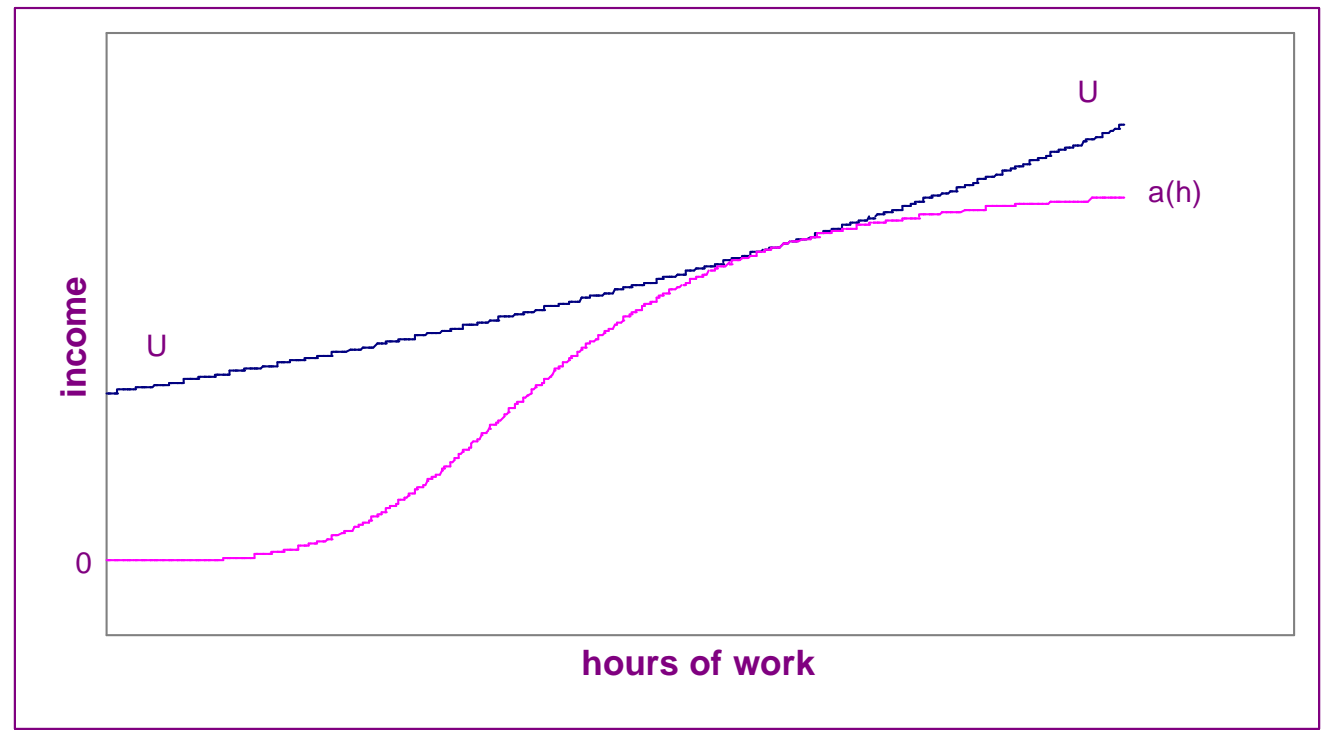

Figure 1b

The Optimal Income-Hours Contract: The Canonical Case

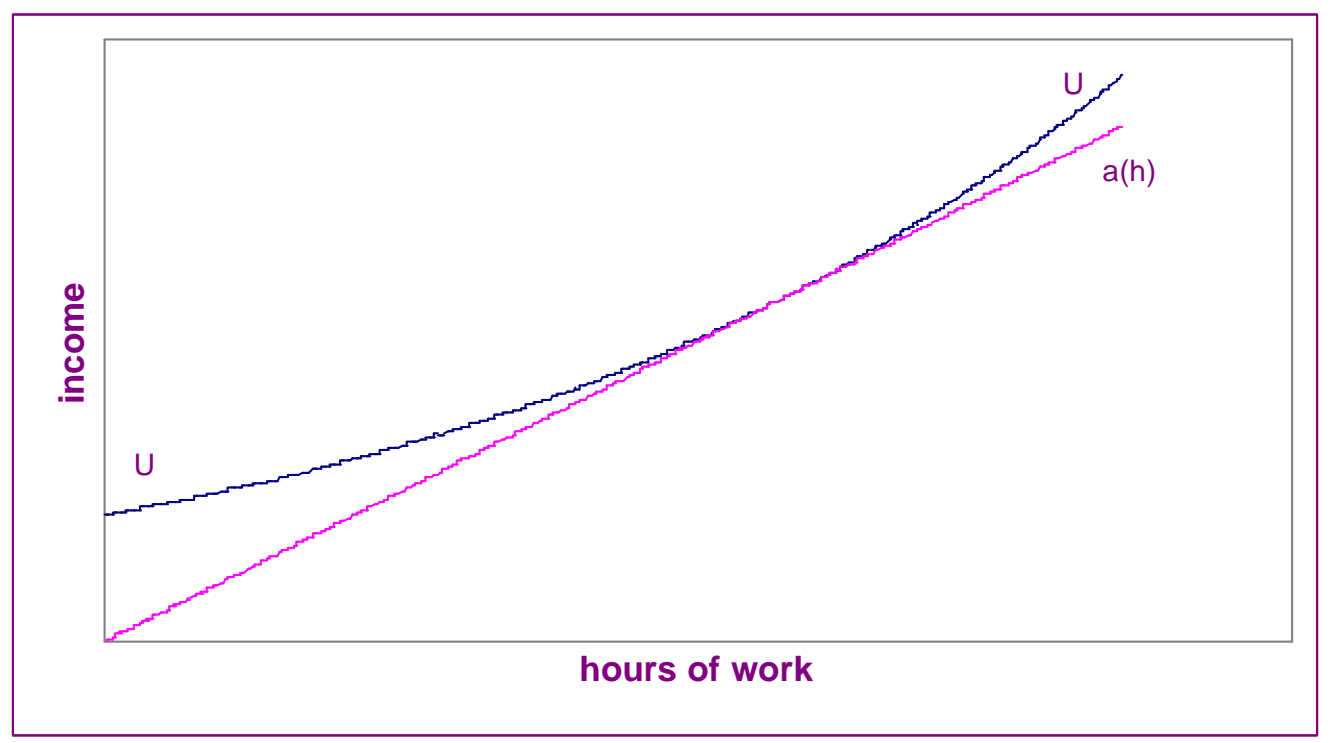


Figure 1c

The Optimal Income-Hours: No Flexibility within Jobs

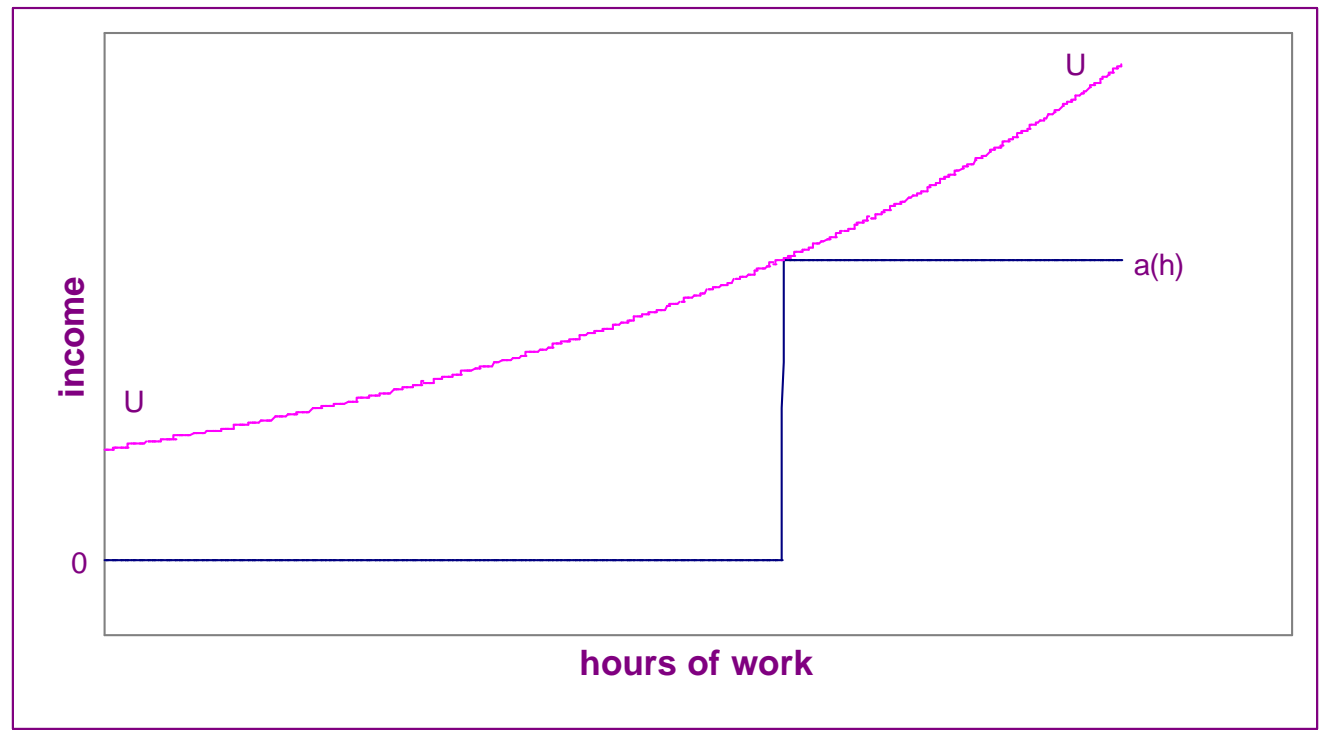


Figure 2a

The Impact of a Change in Average Tax Rates when Leisure is Everywhere Normal

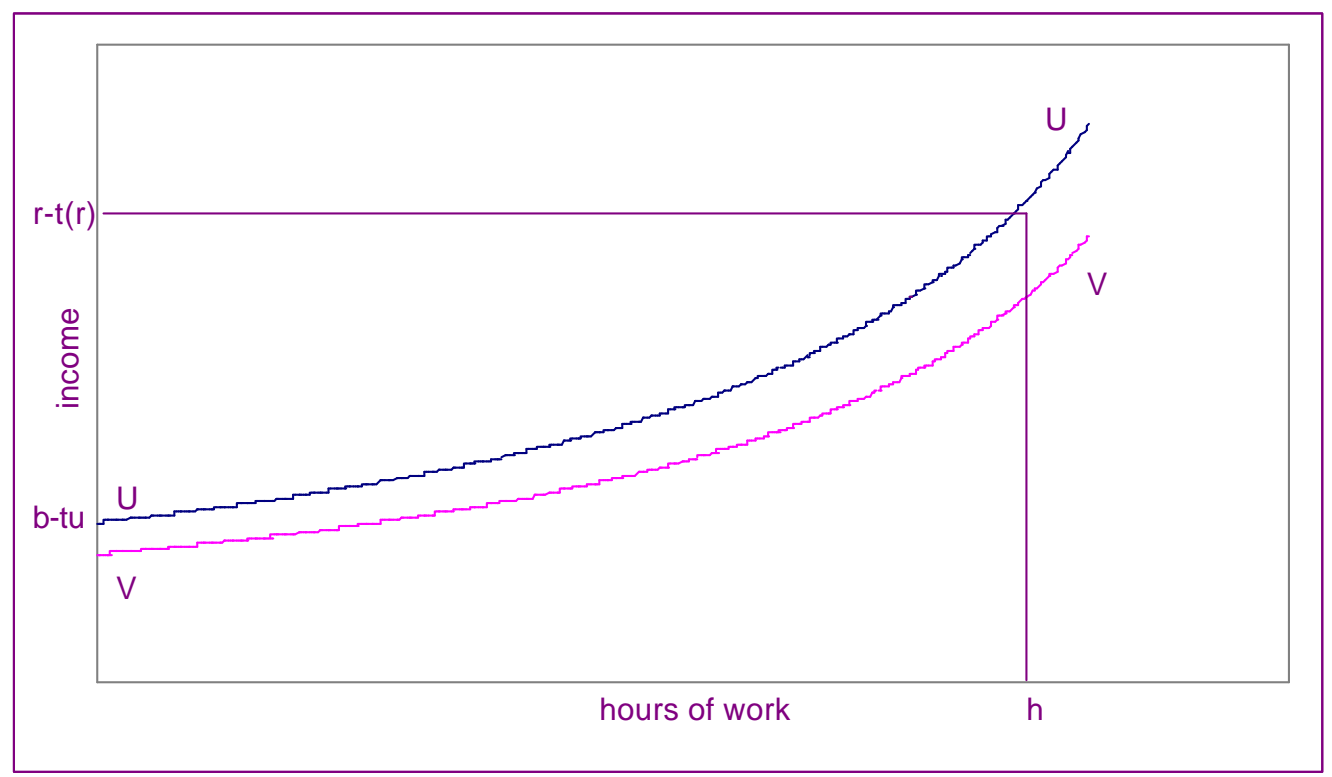

Figure 2b

The Impact of a Change in Average Tax Rates when Leisure is Not Everywhere Normal

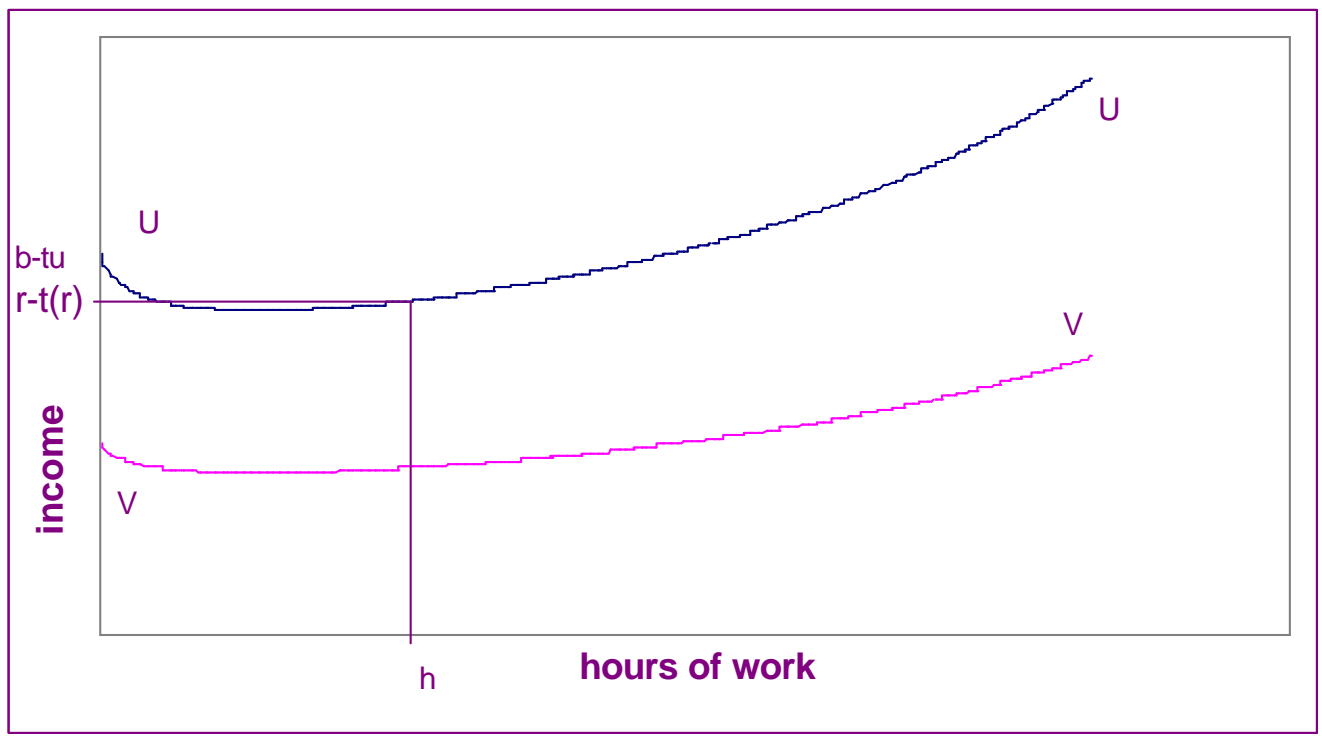


Figure 3

The Impact of a Revenue-Neutral Increase in Marginal Tax Rates

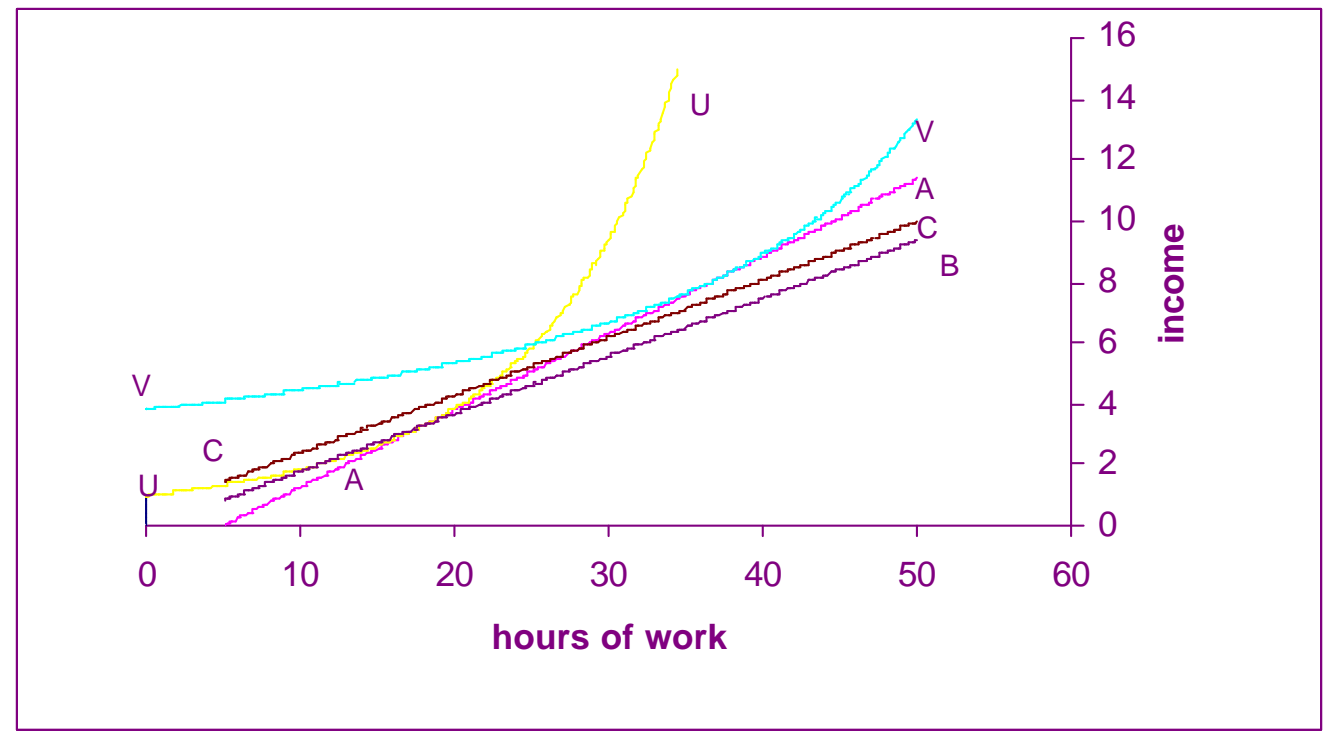




\section{Appendix: Proofs of Propositions}

Proof of Proposition 2a

Using integration by parts, we can write (5) as:

$$
\begin{gathered}
\frac{\mathrm{d} \%_{u}(1 \& F(r))}{\mathrm{d} \%_{e}(1 \& F(r))} \cdot\left(\frac{\mathrm{M}}{\mathrm{M}}\right) \text { ' } \\
{\left[\frac{\mathrm{d} \%{ }_{u}(1 \& F(r))}{\mathrm{d} \% \overbrace{e}(1 \& F(r))} u_{y}(r \& t(r), h) \& u_{y}\left(b \& t_{u}, 0\right) \%\left(?_{u} \& ?_{e}\right){\underset{r}{r}}_{{ }^{y}}(x \& t(x), h) \mathrm{G}(x) d x\right]}
\end{gathered}
$$

where:

$$
\mathrm{G}(x) \quad / \quad \frac{[1 \& F(x)]}{\mathrm{d} \%_{e}[1 \& F(x)]}
$$

First let us consider the case $?_{\mathrm{u}}=?_{\mathrm{e}}$. Then we have that:

$$
\left(\frac{\mathrm{M}}{\mathrm{M}}\right) \quad, \quad u_{y}(r \& t(r), h) \& u_{y}\left(b \& t_{u}, 0\right)
$$

This gives part (i) for Proposition 2a. Now consider how we can make progress in signing this. We know from (13) that, if $?_{\mathrm{u}}=$ ? $\mathrm{e}, \mathrm{u}(\mathrm{r}-\mathrm{t}(\mathrm{r}), \mathrm{h})=\mathrm{u}\left(\mathrm{b}-\mathrm{t}_{\mathrm{u}}, 0\right)$. Consider the function $?$ (h) defined by:

$$
u(?(h), h) \quad ' \quad u_{0}
$$

for some fixed $\mathrm{u}_{0}$. Now consider how $\mathrm{u}_{\mathrm{y}}(?(\mathrm{~h}), \mathrm{h})$ varies as we change $\mathrm{h}$. We have that:

$$
\frac{\mathrm{M} c_{y}(?(h), h)}{\mathrm{M} t}, \quad u_{y y} ?^{\prime}(h) \% u_{y h}, \frac{\& u_{y y} u_{h}}{u_{y}} \% u_{y h}
$$

where the second equality sign follows from the implicit differentiation of (31). If the right-hand side of (32) has the same sign everywhere then this will give the sign of (30). This yields part (ii) of Proposition 2a.

Proof of Proposition $2 b$ :

From (28) we have that, in this case: 


$$
\begin{gathered}
\frac{\mathrm{d} \%_{u}(1 \& F(r))}{\mathrm{d} \%_{e}(1 \& F(r))} \cdot\left(\frac{\mathrm{M}}{\mathrm{M}}\right)< \\
{\left[\frac{\mathrm{d} \%_{u}(1 \& F(r))}{\mathrm{d} \%_{e}(1 \& F(r))} u_{y}(r \& t(r), h) \& u_{y}\left(b \& t_{u}, 0\right) \%\left(?_{u} \& ?_{e}\right){ }_{r}{\underset{m}{y}}_{y}(r \& t(r), h) \mathrm{G}(x) d x\right]} \\
\cdot u_{y}(r \& t(r), h) \& u_{y}\left(b \& t_{u}, 0\right)
\end{gathered}
$$

which gives part (i) of the Proposition.

We know that in this case that $\mathrm{u}(\mathrm{r}-\mathrm{t}(\mathrm{r}), \mathrm{h})>\mathrm{u}\left(\mathrm{b}-\mathrm{t}_{\mathrm{u}}, 0\right)$. If we are prepared to make the assumption that leisure is everywhere a normal good and $u_{1}<0$ then we can sign this using the previous result because we know that if the reservation utility was equal to the level of utility when unemployed the sign would be negative and the fact that the reservation utility is higher, simply further reduces the marginal utility of income at the reservation utility level. This proves part (ii) of the Proposition.

Proof of Proposition 2c:

Using the same approach as in the derivation of (33) we have that:

$$
\begin{gathered}
\frac{\mathrm{d} \%_{u}(1 \& F(r))}{\mathrm{d} \%_{e}(1 \& F(r))} \cdot\left(\frac{\mathrm{M}}{\mathrm{M}}\right)> \\
{\left[\frac{\mathrm{d} \%_{u}(1 \& F(r))}{\mathrm{d} \%_{e}(1 \& F(r))} u_{y}(r \& t(r), h) \& u_{y}\left(b \& t_{u}, 0\right) \%\left(?_{u} \& ?_{e}\right){\underset{r}{r}}_{r} u_{y}(r \& t(r), h) \mathrm{G}(x) d x\right]} \\
\cdot u_{y}(r \& t(r), h) \& u_{y}\left(b \& t_{u}, 0\right)
\end{gathered}
$$

\section{Proof of Proposition 3}

By inspection of (24) and (25) we can see that a rise in marginal tax rates must be accompanied by a fall in $t(r)$ sufficient to make $T(r)$ fall for $\mathrm{T}^{u}$ to be unchanged. Manipulation of (24) and (25) means that we must have:

$$
\left[\mathrm{d} \%{ }_{u}(1 \& F(r))\right] d T(r) \quad ' \quad d t(r) \%\left(?_{e} \& ?_{u}\right) d Z<0
$$

where $\mathrm{dZ}$ is the change in the term involving the marginal tax rates in (24) and (25), $\mathrm{dt}(\mathrm{r})$ is the 
change in the tax burden at the reservation wage and $\mathrm{dT}(\mathrm{r})$ is the change in expected tax revenue from someone employed at the reservation wage.

Now consider the effect of such a change in the tax system on individual's behaviour. If $\mathrm{u}_{\mathrm{y} y}=0$ we can write the utility function as $\mathrm{u}(\mathrm{y}, \mathrm{h})=\mathrm{y}{ }_{{ }_{1}}(\mathrm{~h})+?_{2}(\mathrm{~h})$. Using this utility function in the expression for the reservation wage (13) and differentiating, we have that:

$$
?_{1}(h)[d r \& d t(r)] \& ?_{1}(h) \frac{\left(?_{e} \& ?_{u}\right)[1 \& F(r)]}{\mathrm{d} \%_{e}[1 \& F(r)]} d r \& ?_{1}(h)\left(?_{e} \& ?_{u}\right) d Z \quad ' \quad 0
$$

which can be re-arranged to give:

$$
\frac{\mathrm{d} \%{ }_{u}[1 \& F(r)]}{\mathrm{d} \%_{e}[1 \& F(r)]} d r \quad, \quad d t(r) \%\left(?_{e} \& ?_{u}\right) d Z<0
$$

where the inequality follows from (35). This proves the Proposition.

\section{Proof of Proposition 4}

By differentiating (27) we have that:

$$
\begin{gathered}
{\left[w\left(1 \& t_{y}\right) u_{y}\left(w h_{i} \& t\left(w h_{i}\right) \& t, h_{i}\right) \% u_{h}\left(w h_{i} \& t\left(w h_{i}\right) \& t, h_{i}\right)\right] \frac{\mathrm{M} t_{i}}{\mathrm{M}}} \\
\cdot u_{y}\left(w h_{i} \& t\left(w h_{i}\right) \& \mathbb{t}, h_{i}\right) \& u_{y}\left(b \& t_{u} \& \mathrm{t}, 0\right)
\end{gathered}
$$

where $\mathrm{i}=\mathrm{l}$,u. From Proposition $2 \mathrm{a}$ we know that the sign of the right-hand side of (38) is negative if leisure is everywhere a normal good and $h_{i}>0$. The term in square brackets on the left-hand side of (38) is positive at $h_{l}$ (as hours must be below the optimal level) and negative at $h_{u}$ as hours must be above the optimal level. This proves the Proposition.

\section{Proof of Proposition 5}

If $t(b)$ is left unchanged then from (22) we can see that the effect on $h_{1}$ and $h_{u}$ depends on how $t\left(w h_{l}\right)$ and $\mathrm{t}\left(\mathrm{wh}_{\mathrm{u}}\right)$ change. By definition:

$$
t\left(w h_{u}\right) \quad, \quad t\left(w h_{l}\right) \% w_{h_{l}}^{h_{u}}{\underset{m}{y}}^{t}(w h) d h
$$

We know that $\mathrm{t}_{\mathrm{y}}$ must rise. If $\mathrm{t}\left(\mathrm{wh}_{\mathrm{l}}\right)$ rises then tax revenue will rise at all chosen hours so the change will not be revenue neutral at unchanged behaviour. So $t\left(w h_{1}\right)$ must fall which implies that $h_{1}$ must fall. Now suppose that $t\left(w h_{1}\right)$ falls. Then, from (39) tax revenue must fall at all chosen hours levels so the change cannot be revenue-neutral. So $t\left(w_{u}\right)$ must rise. This means that $h_{u}$ will rise (as utility is decreasing in hours). This proves the Proposition. 


\section{References}

Blundell, R., Ham, J. and Meghir, C. (1987) 'Unemployment and Female Labour Supply', Economic Journal Conference Papers, Vol.97, pp.44-64.

Blundell, R., Ham, J. and Meghir, C. (1987) 'Unemployment, Discouraged Workers and Female Labour Supply’, Research in Economics, Vol.52, pp.103-131.

Blundell, R. and MaCurdy, T. (1998) 'Labor Supply: A Review of Alternative Approaches', forthcoming in Orley Ashenfelter and David Card (eds) Handbook of Labor Economics, volume IV, Amsterdam: North-Holland.

Burdett, K., Kiefer, N.M., Mortensen, D.T. and Neumann, G. (1984) 'Earnings, Unemployment and the allocation of time over time', Review of Economic Studies, Vol.51, pp.559-578.

Burdett, K. and Mortensen, D.T. (1978) 'Labor Supply Under Uncertainty', in Ronald G.Ehrenberg (ed) Research in Labor Economics, Greenwich CT, JAI Press.

Burdett, K. and Mortensen, D.T. (1998) 'Equilibrium Wage Differentials and Employer Size', International Economic Review.

Card, D. (1990) 'Labor Supply with a Minimum Hours Threshold', Carnegie-Rochester Conference Series on Public Policy, Vol.33, pp.137-168.

Clark, A.E. and Oswald, A.J. (1994) 'Unhappiness and Unemployment', Economic Journal, Vol.104(424), pp.648-59.

Cogan, J.F. (1981), 'Fixed Costs and Labor Supply', Econometrica, Vol.49, pp.945-63.

Ham, J.C. (1982) 'Estimation of a Labour Supply Model with Censoring Due to Unemployment and Underemployment', Review of Economic Studies; Vol.49, pp.335-54.

Ham, J.C. (1986) 'On the Interpretation of Unemployment in Empirical Labour Supply Analysis', in R. Blundell and I. Walker (eds) Unemployment, search and labour supply, Cambridge: Cambridge University Press.

Heckman, J.J. (1993) 'What Has Been Learned about Labor Supply in the Past Twenty Years?', American Economic Review, Vol.83(2), pp.116-21.

Lewis, H.G. (1969) 'Employer Interests in Employee Hours of Work', unpublished.

Lockwood, B. and Manning, A. (1993) 'Wage-Setting and the Tax System: Theory and Evidence for the U.K.', Journal of Public Economics, Vol.52, pp.1-30.

Ljungqvist, L. and Sargent, T. J. (1995a) 'Welfare States and Unemployment', Economic Theory, Vol.6(1), pp.143-60. 
Ljungqvist, L. and Sargent, T.J. (1995b) “The Swedish Unemployment Experience”, European Economic Review, 39(5), 1043-70.

Mortensen, D.T. (1977) ‘Unemployment Insurance and Job Search Decisions’, Industrial and Labor Relations Review, Vol.30, pp.505-17.

Mortensen, D.T. and Pissarides, C.A. (1994) 'Job Creation and Job Destruction in the Theory of Unemployment', Review of Economic Studies, Vol.61, pp.397-415.

Narendranathan, Wiji (1993) 'Job Search in a Dynamic Environment-An Empirical Analysis', Oxford Economic Papers, Vol.45, pp.1-22.

Narendranathan, W. and Nickell, S. (1985) 'Modelling the Process of Job Search', Journal of Econometrics, Vol.28(1), pp.29-49.

Pencavel, J. (1986) 'Labor Supply of Men: a Survey', in Orley Ashenfelter and Richard Layard (eds) Handbook of Labor Economics, volume I, Amsterdam: North-Holland.

Pissarides, C.A. (1983) 'Efficiency Aspects of the Financing of Unemployment Insurance and Other Government Expenditure', Review of Economic Studies; Vol.50, pp.57-69.

Pissarides, C.A. (1998) 'The impact of employment tax cuts on unemployment and wages: the role of unemployment benefits and tax structure', European Economic Review, Vol.42, pp.155183.

Stewart, M.B. and Swaffield, J.K. (1997), 'Constraints on the Desired Hours of Work of British Men', Economic-Journal, Vol.107, pp.520-35.

Winkelmann, L. and Winkelmann, R. (1998), 'Why Are the Unemployed So Unhappy? Evidence from Panel Data', Economica, Vol.65, pp.1-16. 